\title{
Volatility Spillover Effects among Securities Exchanges in East Africa
}

\author{
Nelson Yunvirusaba ${ }^{1}$ Jane Aduda $^{2} \&$ Ananda Kube ${ }^{3}$ \\ ${ }^{1}$ Department of Mathematics, Pan African University Institute for Basic Sciences, Technology and Innovation, \\ Nairobi, Kenya \\ ${ }^{2}$ Department of Statistics and Actuarial Science, Jomo Kenyatta University of Agriculture and Technology, \\ Nairobi, Kenya \\ ${ }^{3}$ Department of Statistics and Actuarial Science, Kenyatta University, Nairobi, Kenya \\ Correspondence: Nelson Yunvirusaba, Department of Mathematics, Pan African University Institute for Basic \\ Sciences, Technology and Innovation, P.O. Box 62000, 00200 Nairobi, Kenya. E-mail: \\ yunvirusabanelson@gmail.com
}

Received: August 23, 2019

Accepted: September 9, $2019 \quad$ Online Published: September 10, 2019

doi:10.5539/ijef.v11n10p32

URL: https://doi.org/10.5539/ijef.v11n10p32

\begin{abstract}
This paper aims at examining volatility spillover effects among the returns of three out of the four securities exchanges in East Africa. Vector autoregressive model was used to model return series evolution; and, Johansen co-integration test, was further applied to examine any possibilities of co-integration. Dynamic conditional correlation model was then employed to explore the dynamics of conditional variances. Daily closing all share indices data spanning the period 29 February 2008 to 28 February 2018 was used. The results of the study revealed that, there is bidirectional causality between Nairobi securities exchange and Dar es salaam securities exchange; unidirectional effect between Nairobi securities exchange and Uganda securities exchange; while between Dar es salaam securities exchange and Uganda securities exchange, there is a unidirectional effect. The study findings also indicate evidence of no co-integration, thus, no long-run relationship among the exchanges. The dynamic conditional correlation proved to be the most parsimonious model whose results indicated evidence of volatility spillover among the securities exchanges.
\end{abstract}

Keywords: co-integration, dynamic conditional correlation, East Africa, securities exchanges, volatility spillover effects

\section{Introduction}

World over, every participant in the financial sector is working tirelessly to ensure that success is achieved in every activity; while attempting to minimize risk that could eventually lead to failure. In this regard, if there is one aspect that has caught the attention of market participants, it is volatility of asset returns. Volatility can be defined as a statistical measure of the dispersion of returns for a given security or market index. It can either be measured using the standard deviation or variance between returns from the same security or market index. Kenya, Uganda, Tanzania, Rwanda, Burundi, and South Sudan subscribe to the East African community (EAC) which was founded in 1967. EAC in her pursuit of the integration agenda, has instituted many organs. These include: East African securities regulatory authorities (EASRA), to regulate the securities and East African securities exchanges association (EASEA), responsible for market participants. Undeniably, there is evidence of cross-listing of different companies across the exchanges, most of which originate from Kenya. More specifically, from NSE, nine, five and four entities have been cross-listed to USE, DSE and RSE respectively, making these exchanges inter-twinned to some degree. Owing to the cross-listing initiative and the integration agenda, there is a possibility of price instability emanating from one of the exchanges, eventually spilling over to the rest. The enormity of risk in a portfolio is not totally dependent on the risk of one market's assets, but also on how individual assets from several markets co-evolve. Since investors primarily aim at maximizing profit on their investment, any information highlighting spillovers generates useful insights with regard to diversifying their portfolio. In the same vein, regulators and policy makers would find this information useful to guard against financial contagion. Therefore, this paper generates information useful to several groups of people. Foremost, investors interested in securities in the EAC region will gain information on exposure to shocks within the region. Having knowledge about volatility dynamics across the exchanges is pivotal for selecting their portfolio and 
managing the risk thereon. This paper will also aid policy makers to manage the exchanges during periods of market disturbances. The study is also envisaged to help regulators in performing their oversight roles and finally assisting future researchers interested in volatility spillover and contagion. Notably, previous studies that have handled volatility spillovers between African markets concentrated on the securities exchanges from Middle East North and Southern Africa (MENA); for instance Phume and Bonga-Bonga (2018) studied return volatility spillovers between South African and Nigerian equity markets; Shettima, Gambo, Abraham, Adamu, and Gadanya (2019) studied return and volatility spillovers between Ghanaian and Nigerian equity markets; and then, El Ghini and Saidi (2017) who studied return and volatility spillovers in the Moroccan stock market during the financial crisis. In spite of that, very little is known about volatility transmission among the securities exchanges in East Africa. Consequently, this paper attempts to fill this gap.

\subsection{Overview of Securities Exchanges in East Africa}

The East African region has four operational securities exchanges. These are; Nairobi securities exchange (NSE) in Kenya, Dar es salaam securities exchange in Tanzania (DSE), Uganda securities exchange in Uganda (USE) and Rwanda stock exchange (RSE) in Rwanda. A total of one hundred eighteen companies are listed on the four exchanges; sixty three on NSE, nine on the RSE, twenty eight on the DSE, and eighteen on USE. In terms of market capitalization, NSE has Kenya shillings 2,290.73 billions, USE with Uganda shillings 21,801.83 billions, DSE with Tanzania shillings 19,110.90 billions and RSE having Rwanda Francs 3,056.83 billions. Some of the companies are cross-listed on all the exchanges which include, National Media group, Kenya Commercial Bank, British American Tobacco and Jubilee holdings limited. This paper therefore discusses dynamic linkages among three out of the four securities exchanges in the East African region. Rwanda securities exchange was omitted from this study because it became operational in 2011 long after the rest of the exchanges had been established, thus could not give data sufficient for this study.

\subsection{Related Literature}

According to Bala and Takimoto (2017), the global financial crisis of 2008 and its impact across financial markets triggered considerable interest in research focusing on analysis of volatility spillovers in stock markets. The financial crisis which started initially as an incident in the United States of America, spread to many markets. Major stock markets were destabilized, and subsequently emerging markets causing significant losses for investors, leading to bankruptcies of many financial institutions and decline in investor confidence, thus, adversely affecting the global economy. The authors further argued that the ever-increasing globalization of financial markets and the incidence of crises, large stock market fluctuations, and market crashes that spanned from the Mexican crisis, Asian crisis, Brazilian currency crisis to the Greek debt crisis regenerated the interest on how financial markets within and across countries interact and how volatility spills over from one market to the others.

According to Liebenberg (2012), co-movement existing among any stock markets can be attributed to several factors which include; economic integration, contagion effects and identical market characteristics. Contagion effects usually emanate from non-economic fundamentals for instance investor psychology influenced by self-fulfilling expectations causing markets to shift into the state of bad equilibrium and spreading the same to other markets. This manifests when there is high correlation during periods of crisis. Mensi, Beljid, Boubaker, and Managi (2013) in the study of correlations and volatility spillovers across commodity and stock markets found significant transmission among S\&P500 and commodity markets; with the past shocks and volatility of S\&P500 strongly influencing the oil and gold markets. Their study employed the vector autoregressive-GARCH model to investigate the return links and volatility transmission between S\&P500 and the commodity price indices for energy, food, gold and beverages over the period 2001 to 2011.

$\mathrm{Li}$ and Giles (2015) in their paper observed significant unidirectional shock and volatility spillovers from the US market to both the Japanese and the Asian emerging markets. They also found out the volatility spillovers between the US and the Asian markets were stronger and bidirectional during the Asian financial crisis. The authors examined the linkages of stock markets across the USA, Japan and six Asian developing countries which included China, India, Indonesia, Malaysia, the Philippines and Thailand over the period January 1993 to December 2012. Asymmetric multivariate generalized autoregressive conditional heteroscedastic models were used to model the volatility spillover.

Gulzar et al. (2019) studied financial co-integration and spillover effect of the global markets of the global financial crisis to emerging Asian financial markets of India, China, Pakistan, Malaysia, Russia and Korea. Johansen co-integration test, the vector error correction model were employed for examination of integration. Further, the BEKK-GARCH model was used to examine the dynamics of conditional volatility. The study found 
long term co-integration between the U.S market and the emerging stock markets. Phume and Bonga-Bonga (2018) in their study of return and volatility spillovers between Nigerian and South African equity markets made an evaluation of cross-transmissions and volatility spillovers among stock markets from the two countries. The authors employed AVAR GARCH model whose results indicated that return and volatility spillovers from South Africa to Nigerian stock markets are unidirectional, such that returns from South African stock markets to those in Nigeria were statistically significant while those from Nigeria to South African Stock markets were not statistically significant. The authors further noted that Nigerian stock markets were susceptible to asymmetric volatility effects while South African stock markets were not. Kirkulak and Ezzat (2017) studied volatility spillover effect in MENA stock markets in the pretext of the Egyptian revolution. Stock markets of Egypt, ISrael, Saudi Arabia and Turkey were considered. The study jointly employed BEKK and DCC GARCH models to examine spillovers across the markets. The authors noted that the Egyptian stock markets' volatility drove the dynamics of the rest of the stock markets in the region during the revolution. It was further noted that Israel and Saudi Arabia were more sensitive to the shocks; which was attributed to integration of stock markets in MENA region. Shettima et al. (2019) examined return and volatility spillovers between Nigerian and Ghanaian equity markets. VARMA-AMGARCH was employed to the return series for the two markets. The authors noted that there was significant cross-transmission between the two stock market return and volatility spillovers. However, it was further noted that Ghanaian stock market volatility was more sensitive to that of Nigerian stock market. Additionally, both markets were more susceptible to own shocks than those spilling over from across the boarder.

Kuttu (2014) examined return dynamics and volatility transmission among the equity markets of Ghana, Kenya, Nigeria and South Africa. The study employed a multivariate vector autoregressive EGARCH model. The authors noted that there was exhibition of reciprocal return spillover as follows: between Kenya and Ghana; and then Nigeria and South Africa. They also noted that South Africa was dominant in exporting past return innovations to Kenya and Nigeria, making South Africa play a significant role in providing information to the equity markets of Nigeria and Kenya considerably. It was however noted that, except South Africa, Nigeria transmitted volatility to Ghana and Kenya. Kenya was found to have significant leverage effect in Ghana stock markets. Finally, the authors noted that own market volatility was more pronounced than volatility spillovers from other markets. We note that most of the studies that have delved into analysis of volatility spillover have focused on the dynamics among developed markets; and from developed markets to emerging ones. A minor segment that has focused on some of the frontier markets in Africa have concentrated on markets that have made significant strides in market capitalization and other indicators of growth such as market capitalization to GDP. These include Johannesburg stock exchange from South Africa, Tunisia, Egypt and Morocco. To the best of our knowledge, no such a study aiming at modeling volatility dynamics in securities exchanges in the East African region has been done.

\section{Econometrics Methodology}

\subsection{VAR}

A VAR model describes the evolution of a set of $n$ variables over the same period as a linear function of only their past values. For instance, a $k^{t h}$ order VAR denoted $\operatorname{VAR}(k)$ is given by;

$$
y_{t}=C+\sum_{i=1}^{k} A_{i} y_{t-i}+a_{t}
$$

where $y_{t}$ is a column vector of variables under investigation, $C$ is a $k \times 1$ column vector of constants; $A_{i}$ is a $k \times k$ coefficient matrix; and $a_{t}$ is a $k \times 1$ column vector of errors such that: $a_{t} \mid \mathrm{F}_{t-1} \sim N\left(0, \Sigma_{t}\right)$ where $\Sigma t$ is a positive definite covariance matrix and $\mathrm{F}_{t-1}$ is a set of past information. By applying first differencing to (1) and reparameterizing, it can be shown that (1) can be written as

$$
\Delta y_{t}=\Pi y_{t-1}+\sum_{i=1}^{k-1} \Gamma_{i} \Delta y_{t-i}+a_{t}
$$

where $\Pi$ is an impact matrix of dimension $k \times k$ and is defined as $\Pi=\Pi_{1}+\Pi_{2}+\cdots+\Pi_{k}-I_{k}$ and $\Gamma_{i}=-\sum_{i=j+1}^{k} \Pi_{j}$ with $j=1,2, \cdots, k-1 ; I_{k}$ is an identity matrix of order $k$. From (2), the rank $(r)$ of $\Pi$ is evaluated to ascertain the presence of co-integration. If $r=0$, there is no co-integration and thus no stable long-run relationship between variables but rather VAR in differences. With $r=k$, the variables are stationary in levels; while with, $r<k$, there is co-integration and so, a vector error correction model (VECM) can be estimated. The paper applies the Johansen co-integration test proposed by Johansen (1991). This test is premised on examining the coefficient matrix, П, so that the testing of for co-integration between variables is achieved by examining the rank of $\Pi$ through the 
eigenvalues. This paper applies the trace test which is one of the tests. The hypothesis of the trace test states that the number of co-integrating vectors is less than or equal to the rank $r$ against the alternative that the co-integrating vectors are more than $r$. The hypothesis is nested and thus stated as follows;

$$
H_{0}(r): r=r_{0} \text { versus } H_{1}(r): r>r_{0}
$$

The trace statistic is given by;

$$
L_{\text {trace }}=-T \sum_{i=r+1}^{n} \ln \left(1-\widehat{\lambda}_{l}\right)
$$

where $T$ is the number of observations and $\widehat{\lambda}_{i}$ represents the estimated eigenvalues.

\subsection{Granger Causality}

This technique is used to determine whether one time series is useful in forecasting another. A variable $X t$ is said to Granger-cause $Y t$, if the variable $Y t$ can be better predicted with more accuracy by using past values of the $X t$ in the presence of past values of $Y t$. This is demonstrated by (5)

$$
y_{t}=\alpha+\sum_{i=1}^{m} \beta_{i} Y_{t-i}+\sum_{j=1}^{n} \gamma_{j} Y_{t-j}+u_{t}
$$

This test is premised on the standard F-test whose test statistic is given by

$$
F=\frac{R S S E-U S S E}{U S S E}\left(\frac{T-k}{q}\right)
$$

where RSSE denotes sum of squared errors from the restricted model; USSE, the sum of squared errors from the unrestricted model; $T$ denotes the sample size, $k$ denotes number of lags and $q$ the number of restrictions used. The null hypothesis is $\gamma_{1}=\gamma_{1}=\cdots=\gamma_{n}=0$ against the alternative of some $\gamma_{j} \neq 0$.

\subsection{Conditional Correlation Representation}

This type of models is based on modelling conditional correlations and conditional variances. Bollerslev (1990) introduced the constant conditional correlation model. This is based on the assumption that the dynamic conditional covariances are proportional to the product of the corresponding conditional standard deviations. This however, has a limitation of not allowing for spillover effects although it is simpler to estimate due to lower number of parameters. Engle (2002) proposed a dynamic conditional correlation model which overcomes the limitation of the constant conditional correlation model by allowing for dynamic linkages between variables. Generally, a multivariate GARCH model is defined as:

$$
y_{t}=\mu_{t}+a_{t}
$$

and

$$
a_{t}=\sum_{t}^{1 / 2} \varepsilon_{t}
$$

where $y_{t}$ is a vector of series under investigation, $\mu_{t}$ is a vector of means for the series, say $k$ series, $\sum_{t}^{1 / 2}$ is the square root of the covariance matrix and can be obtained by Cholesky decomposition of the conditional covariance matrix $\Sigma t ; \varepsilon_{t}$ is unobservable random vector whose moments are $\mathrm{E}\left(\varepsilon_{t}\right)=0$ and $\operatorname{Var}\left(\varepsilon_{t}\right)=\mathrm{E}\left(\varepsilon_{t} \varepsilon_{t}^{T}\right)=I_{n}$ where $I_{n}$ is an identity matrix of order $n$. The specification of the DCC is given by;

$$
\Sigma_{t}=D_{t} R_{t} D_{t}
$$

where $D_{t}=\operatorname{diag}\left(\sigma_{1 t}, \sigma_{2 t}, \cdots, \sigma_{k t}\right)$ and $R_{t}$ the dynamic conditional correlation is obtained by

$$
R_{t}=\operatorname{diag}\left(q_{11 t}^{-\frac{1}{2}}, q_{22 t}^{-\frac{1}{2}}, \ldots, q_{k k t}^{-\frac{1}{2}}\right) Q_{t} \operatorname{diag}\left(q_{11 t}^{-\frac{1}{2}}, q_{22 t}^{-\frac{1}{2}}, \ldots, q_{k k t}^{-\frac{1}{2}}\right)
$$

where $Q_{t}$ is a symmetric positive definite matrix given by $\left(q_{i j t}\right)$ defined as

$$
Q_{t}=(1-\alpha-\beta) \bar{Q}+\alpha \varepsilon_{t} \varepsilon_{t}^{T}+\beta Q_{t-1}
$$

$\alpha$ and $\beta$ are non-negative scalar parameters such that $\alpha+\beta<1$. The constant conditional correlation model differs from the dynamic conditional correlation by having correlation matrix as static.

\section{Results and Discussion}

\subsection{Descriptive Statistics}

The study used secondary data. Daily closing prices of Nairobi securities exchange all share index, Uganda 
securities exchange all share index and Dar es salaam securities exchange spanning the period 29 Feb 2008 to 28 Feb 2018 were used. The missing values were addressed by replacing them with the values from the prior day when the markets were open. According to Tsay (2010) majority of financial studies use asset returns instead of asset prices because; for an investor, the return represents a complete and scale-free summary of the investment opportunity and return series also have desirable statistical properties. From the all share market indices, continuously compounded log returns were generated using:

$$
r_{t}=\ln \left(\frac{p_{t}}{p_{t-1}}\right)
$$

where $p_{t}$ denotes the current closing market index and $p_{t-1}$ the market index for the previous trading day. The data was obtained from Nairobi securities exchange, Dar es salaam securities exchange and Uganda securities exchange.

Some descriptive statistics were obtained describing the behaviour of returns for the exchanges. Table 1 gives a summary of descriptive statistics along with the Jaque-Bera test for normality of the return series data. The null hypothesis for the JB test for normality is that the data are i.i.d as normal implying the skewness and excess kurtosis are both zero: against the alternative of non-conformity to the normal distribution. From the measure of skewness, we see, the series of NSE, USE, and DSE are skewed to the right implying that large positive changes in returns occur more often than positive changes. From the measure of kurtosis, the return series are all leptokurtic. This indicates that the tails have more observations than in a Gaussian distribution which was confirmed by the Jarque-Bera test.

Table 1. Descriptive statistics of NSE, USE and DSE return series

\begin{tabular}{lccc}
\hline & NSE & USE & DSE \\
\hline Mean & 0.000236 & 0.000326 & 0.000311 \\
Median & 0.0000 & 0.0000 & 0.0000 \\
Maximum & 0.074857 & 0.168475 & 0.202724 \\
Minimum & -0.051408 & -0.152169 & -0.163230 \\
St.dev & 0.008086 & 0.015347 & 0.016363 \\
Skewness & 0.548702 & 0.278412 & 0.692677 \\
Kurtosis & 11.309683 & 22.353842 & 42.552383 \\
JB & 13988 & 54158 & 196310 \\
\hline
\end{tabular}

Figure 1, 2 and 3 below present daily closing all share indices and their returns for the three securities exchanges. Daily returns fluctuate around zero visually indicating stationarity of the return series. The time plot for daily log returns further shows periods of high volatility and low volatility following each other signifying volatility clustering of the returns which is one of the stylized characteristics of returns.
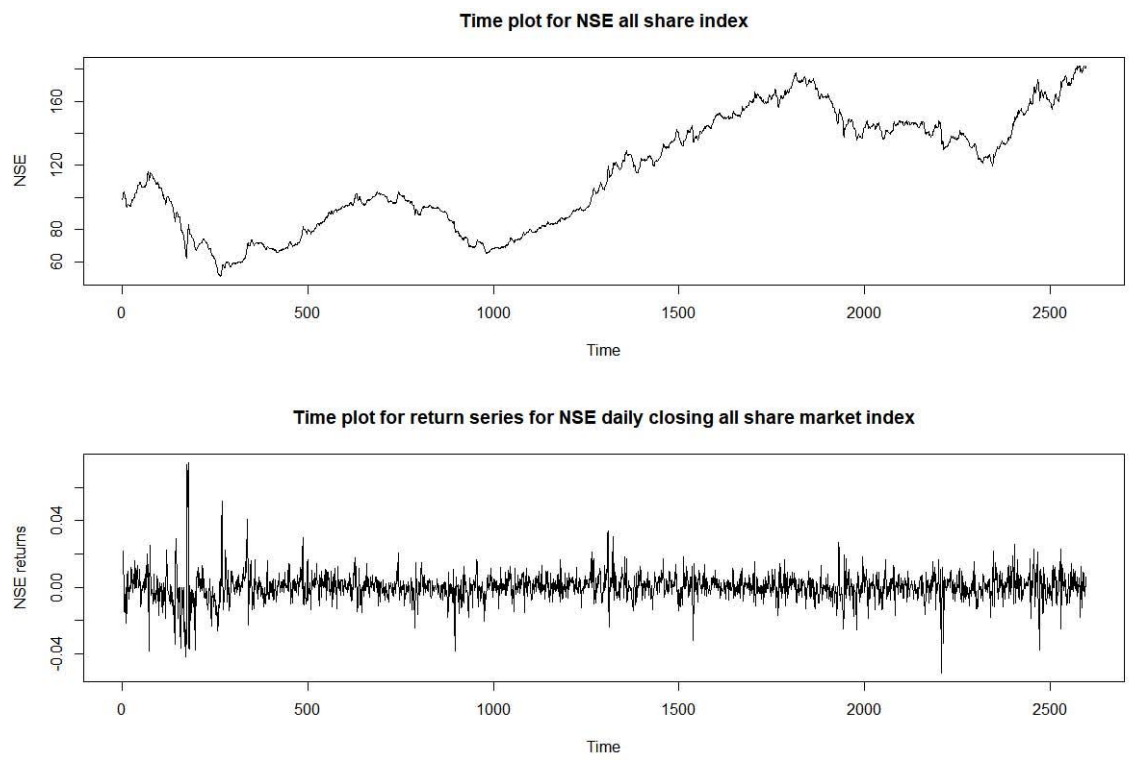

Figure 1. Time plot for NSE all share index and its return series 


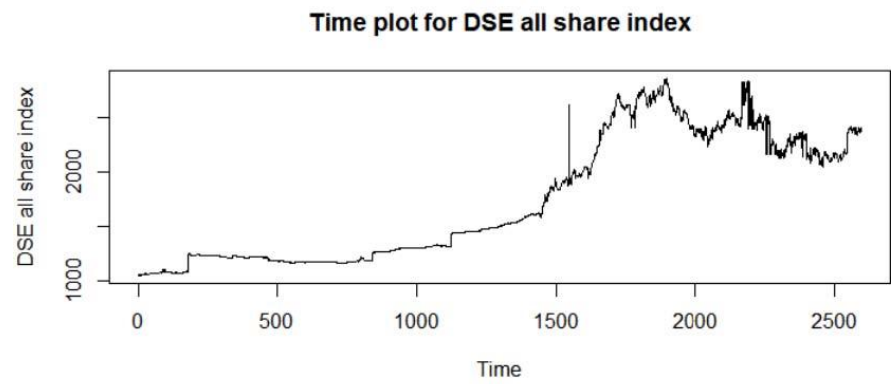

Time plot for DSE all share index returns

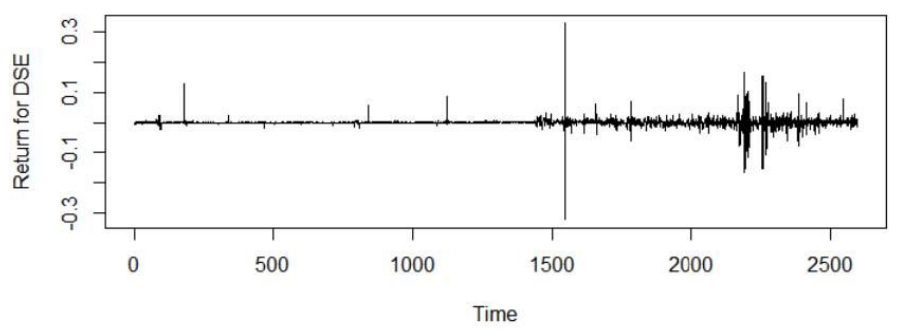

Figure 2. Time plot for DSE all share index and its return series

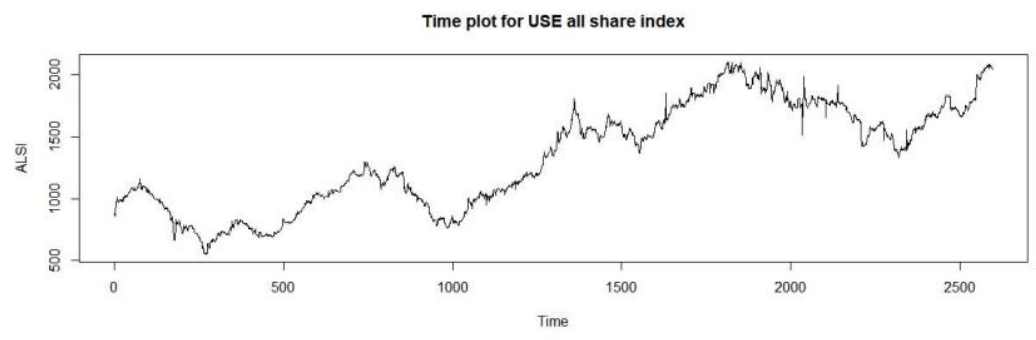

Time plot for return series for USE daily closing all share market index

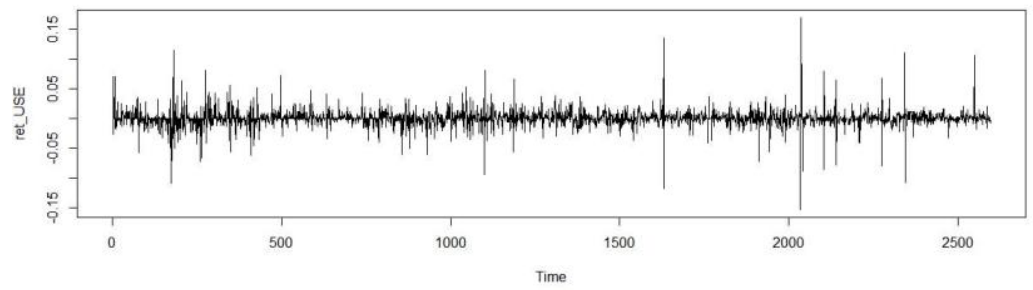

Figure 3. Time plot for USE all share index and its return series

In addition to visually inspecting the time plot of the log return series of the all share indices of the exchanges, they were tested for stationarity using the Augumented Dickey-Fuller test whose results are displayed in Table 2. The p-values emanating from the table indicate sufficient evidence to reject the null hypothesis that the return series are non-stationary. Therefore, the log return series for the three exchanges were stationary at $5 \%$ level of significance. Since stationarity is a desirable property for time series analysis, the return series were subjected to further time series analysis.

Table 2. Stationarity test for the return series

\begin{tabular}{lccc}
\hline P-value & & Test-statistic & Decision \\
\hline NSE & $<0.01$ & -12.686 & Reject H0 \\
DSE & $<0.01$ & -15.394 & Reject H0 \\
USE & $<0.01$ & -13.19 & Reject H0 \\
\hline
\end{tabular}




\subsection{Granger Causality}

In this study, the results of Granger causality in return series have been reported in Table 3. From Table 3, we see bidirectional causality between NSE and DSE; while we also observe from the same table unidirectional effects between DSE and USE. Between NSE and USE, the results indicate presence of unidirectional effects. This means that past information from NSE all share index is needed while forecasting the all share indices of USE and DSE. In the same vein, past information of DSE all share index is useful while forecasting the NSE all share index. Whereas for the securities exchange with unidirectional effects, that is, the results indicate that past information about NSE all share index is important while forecasting USE all share index but not the other way round. Similarly, past information on USE all share index is useful while forecasting the DSE all share index but not the other way round. Overall, NSE all share index Granger causes all indices of the other securities exchanges. This can be attributed to factors such as; NSE being the largest in size among all the exchanges. It can also be argued that, NSE being more liquid and relatively more stable, traders would find it easier to invest and dispose of their portfolios on NSE than other exchanges.

Table 3. Results from the Granger causality $(F)$ test on the return series

\begin{tabular}{lccc}
\hline NSE & & DSE & USE \\
\hline NSE & & $6.4066(0.0002543)$ & $86.209(0.0000)$ \\
DSE & $3.3308(0.01878)$ & & $1.8741(0.1318)$ \\
USE & $0.6798(0.5644)$ & $3.1986(0.0225)$ & \\
\hline
\end{tabular}

Note. p-values are indicated in the parenthesis.

\subsection{Co-Integration}

Using the Johansen co-integration trace test, the rank of the impact matrix $\Pi$ was examined. The testing was done sequentially with the first instance of non rejection of the null hypothesis being the estimate for $r$. In this case, there is no sufficient evidence to reject the null hypothesis that there is no co-integration at $5 \%$ level of significance. Accordingly, there are no co-integrating relations among the three securities exchanges' all share indices. The results are displayed in Table 4. Therefore, the three exchanges do not have long run equilibrium relations but only short run ones. This is agrees with Aduda (2017) who stated that even when variables are not co-integrated in the long-run, they could still be related in the short-run. Following from having no co-integration among the exchanges, the vector error correction model is not possible. Accordingly, a vector autoregressive model was fitted to the return series of all share indices for the three securities exchanges.

Table 4. Results obtained from Johansen co-integration test

\begin{tabular}{lccc}
\hline Rank & Test-stat & Critical value (5\%) & Decision \\
\hline$r=0$ & 27.97 & 31.52 & Reject H0 \\
$r=1$ & 8.65 & 17.95 & Reject H0 \\
$r=2$ & 0.01 & 8.18 & Reject H0 \\
\hline
\end{tabular}

\subsection{VAR Model Results}

Different criteria were used to select optimal lag length of the VAR model whose results are displayed in Table 5. In a simulation study by Liew (2004), it was argued that performance of each of the criterion depends on the the size of the sample to which they are applied. The study noted that for small samples, the Akaike information criterion and final prediction error achieve the best results whereas for large samples, Hannan-Quinn criterion and Schwarz information criterion achieve the best results. Therefore, this study uses Schwarz information criterion since it outperforms all other criteria for larger samples. Accordingly, the study chooses the optimal lag length for the VAR model as 2. Therefore, a vector autoregressive model of order two was fitted to the return series data whose results displayed in Table 5. From Table 5, there is evidence of feedback mechanism between Nairobi securities exchange and Dar es salaam securities exchange. As for Uganda securities exchange and Dar es salaam securities exchange, there is evidence of unidirectional mechanism between the indices' returns. The residuals of the VAR(2) model were inferred and tested for the presence of serial and cross-correlations using the multivariate Portmanteau test. The results are displayed in Table 6. There was no sufficient evidence to reject the null hypothesis of no significant serial and cross-correlation in the residuals of the VAR(2) model. The multivariate ARCH-Lm test was further applied to the ręsiduals of the VAR(2) model to establish the presence of ARCH and from results emanating from the same $(\chi=3278.9, p-$ value $<0.001)$, we did not have sufficient 
evidence to reject the null hypothesis of the residuals possessing significant ARCH effects at $5 \%$ level of significance. As such, GARCH type models were suitable to model the volatilities of the return series of the indices. More precisely, since we are dealing with three markets, multivariate GARCH models are suitable for modelling the conditional variances of the return series from the exchanges.

Table 5. Results obtained from the VAR(2) Model

\begin{tabular}{lcccc}
\hline Parameter & Estimate & Standard error & t-value & $\operatorname{Pr}(>|t|)$ \\
\hline$r 1 . l 1$ & 0.464081 & 0.19644 & 23.624 & 0.00000 \\
$r 2 . l 1$ & -0.024381 & 0.009070 & -2.688 & 0.00723 \\
$r 3 . l 1$ & -0.023569 & 0.009435 & -2.498 & 0.01255 \\
$r 1 . l 2$ & 0.009235 & 0.020112 & 0.459 & 0.64615 \\
$r 2 . l 2$ & 0.003659 & 0.009080 & 0.403 & 0.68700 \\
$r 3 . l 2$ & -0.004719 & 0.009300 & -0.507 & 0.61192 \\
$r 1 . l 1$ & 0.096836 & 0.041792 & 2.317 & 0.0206 \\
$r 2 . l 1$ & -0.383362 & 0.019296 & -19.867 & 0.00000 \\
$r 3 . l 1$ & 0.009194 & 0.020072 & 0.458 & 0.6470 \\
$r 1 . l 2$ & 0.054845 & 0.042788 & 1.282 & 0.2000 \\
$r 2 . l 2$ & -0.193797 & 0.019318 & -10.032 & 0.00000 \\
$r 3 . l 2$ & 0.008294 & 0.019786 & 0.419 & 0.6751 \\
$r 1 . l 1$ & 0.33013 & 0.04069 & 8.113 & 0.00000 \\
$r 2 . l 1$ & 0.02074 & 0.01879 & 1.104 & 0.26964 \\
$r 3 . l 1$ & -0.15474 & 0.01954 & -7.918 & 0.00000 \\
$r 1 . l 2$ & 0.14662 & 0.04166 & 3.519 & 0.00044 \\
$r 2 . l 2$ & 0.02842 & 0.01881 & 1.511 & 0.13096 \\
$r 3 . l 2$ & -0.00225 & 0.01927 & -0.117 & 0.90703 \\
\hline
\end{tabular}

Note. $r 1$ denotes the NSE all share index return; $r 2$ the DSE all share index return, and $r 3$ the USE all share index return while.$l 1$ and.$l 2$ denotes the first and second lags respectively.

Table 6. Results of Multivariate Portmanteau test for autocorrelation in the residuals of VAR(2)

\begin{tabular}{lcccr}
\hline Variable & $\mathrm{m}$ & $Q(m)$ & df & p-values \\
\hline NSE & 1 & 0.532 & 9 & 1.00 \\
DSE & 2 & 6.400 & 18 & 0.99 \\
USE & 3 & 29.358 & 27 & 0.34 \\
\hline
\end{tabular}

\subsection{Volatility Spillover Using DCC Model}

The estimated results from the DCC model in which the conditional variance of the residuals is modelled as a function of past realizations of both volatility of the three return series for the exchanges and correlations between them. Since $\sigma i, t$ is assumed to follow a univariate $\operatorname{GARCH}(1,1)$ process, the coefficient $A_{i i}$ represents ARCH effects and $B_{i i}$ GARCH effects. The estimated DCC $(1,1)$ parameters are displayed in Table 5. The estimated ARCH parameters $\left(A_{i i}\right)$ and GARCH parameters $(B i i)(i=1,2,3)$ are all statistically significant at $5 \%$ level of significance. Statistically significant parameters $B_{i i}$ indicate that volatility transmission is bi-directional among the indices. The estimated $\alpha$, a parameter denoting joint significance of ARCH parameters, and $\beta$ denoting joint significance of GARCH parameters, are larger than zero meaning that conditional correlation among the indices returns is not constant. The results further indicate that the DCC was a good fit for the data due to the joint significance of the ARCH and GARCH parameters. In fact, since the sum of the estimated values of $\alpha$ and $\beta$ is close to one, then the conditional variances exhibit a highly persistent behavior. Nonetheless, since the sum is less than one, then the dynamic conditional correlations are slowly mean-reverting. The magnitudes of the parameters $\alpha$ and $\beta$ indicate that the evaluation of the conditional covariance depends more on the past values of conditional variance than on lagged residuals' innovations. The model provides statistically significant evidence for the existence of volatility spillover effects owing to the joint significance of ARCH and GARCH parameters indicating that dynamic conditional correlations are highly dynamic and time varying. This nullifies the assumption of constant conditional correlations which is consistent with the evidence in literature for example Bauwens, Laurent, and Rombouts (2006) criticized the assumption of conditional correlations being constant and eventually end up being unrealistic in many empirical applications. 
Table 7. Results obtained from the DCC-GARCH

\begin{tabular}{lcccr}
\hline Parameter & Estimate & St.error & t-value & $\operatorname{Pr}(>|t|)$ \\
\hline$\mu_{1}$ & 0.000511 & 0.000131 & 3.90954 & 0.000092 \\
$\omega_{1}$ & 0.000005 & 0.000001 & 7.94227 & 0.00000 \\
$A_{11}$ & 0.271943 & 0.028791 & 9.44535 & 0.00000 \\
$B_{11}$ & 0.648975 & 0.028134 & 23.06723 & 0.00000 \\
$\mu_{2}$ & 0.000262 & 0.000463 & 0.56475 & 0.572246 \\
$\omega_{2}$ & 0.000001 & 0.000001 & 0.62856 & 0.529637 \\
$A_{22}$ & 0.100231 & 0.022918 & 4.37338 & 0.000012 \\
$B_{22}$ & 0.898769 & 0.012403 & 72.46345 & 0.00000 \\
$\mu_{3}$ & 0.000422 & 0.000291 & 1.45145 & 0.146653 \\
$\omega_{3}$ & 0.000050 & 0.000015 & 3.33149 & 0.000864 \\
$A_{33}$ & 0.155107 & 0.032519 & 4.76971 & 0.000002 \\
$B_{33}$ & 0.623431 & 0.066145 & 9.42527 & 0.00000 \\
$\alpha$ & 0.002683 & 0.001522 & 1.76269 & 0.0077952 \\
$\beta$ & 0.992580 & 0.003183 & 311.80777 & 0.00000 \\
\hline
\end{tabular}

\section{Conclusion}

This study examined the dynamic relationship among Nairobi securities exchange, Uganda securities exchange and Dar es salaam securities exchange using daily all share index data from 29 February 2008 to 28 February 2018. The primary purpose of the paper was to examine possibility of spillovers in conditional variances across the three exchanges. The study used the vector autoregressive model for the mean equation and the dynamic conditional correlation for the conditional volatilities. Johansen co-integration trace test was used to test for co-integration in all share indices data for the three exchanges. The indices were also tested for Granger causality and results reveal the following:

There is bidirectional causality between Nairobi securities exchange and Dar es salaam securities exchange; unidirectional effect between Nairobi securities exchange and Uganda securities exchange, and between Dar es salaam securities exchange and Uganda securities exchange, there was a unidirectional effect. There was no evidence of co-integration among all share indices for the three exchanges. The DCC $(1,1)$ turned out to be the most parsimonious model since the joint $\mathrm{ARCH}$ and GARCH parameters were jointly significant. The presence of Granger causality but no co-integration gives evidence of the three exchanges being related in the short run but no long run equilibrium relationship exists among them. Owing to the joint significance of the ARCH and GARCH parameters of the $\operatorname{DCC}(1,1)$ model, then there is evidence of volatility spillover among Nairobi securities exchange, Dar es salaam securities exchange and Uganda securities exchange. Presence of volatility spillovers among the exchanges indicates that they are vulnerable to shocks from each other, and some degree of interdependence. However, the results of Granger causality were in favor of Nairobi securities exchange; making it have greater influence on the other exchanges. In fact, Dar es salaam securities exchange and Uganda securities exchange are more sensitive to Nairobi securities exchange. This implies that a high level of volatility in Nairobi securities exchange increases levels of anxiety for investors from the other exchanges in the region. The paper recommends a further study aiming at forecasting conditional volatilities for the securities exchanges in the East African region using the symmetric DCC and asymmetric DCC to establish which model yields better forecasts.

\section{Acknowledgements}

The authors are most grateful to the anonymous reviewer and editor whose comments refined this paper. We would be failing in our obligation if we did not extend our appreciation to African Union that funded this research.

\section{References}

Aduda, J. A. (2017). Application of multivariate volatility models in estimating optimal dynamic hedge ratios for crack spreads with volatility spillovers in energy markets.

Bala, D. A., \& Takimoto, T. (2017). Stock markets volatility spillovers during financial crises: A dec-mgarch with skewed-t density approach. Borsa Istanbul Review, 17(1), 25-48. https://doi.org/10.1016/j.bir.2017.02.002

Bauwens, L., Laurent, S., \& Rombouts, J. V. (2006). Multivariate garch models: a survey. Journal of Applied 
Econometrics, 21(1), 79-109. https://doi.org/10.1002/jae.842

Bollerslev, T. (1990). Modelling the coherence in short-run nominal exchange rates: A multivariate generalized arch model. The review of economics and statistics, 498-505. https://doi.org/10.2307/2109358

El Ghini, A., \& Saidi, Y. (2017). Return and volatility spillovers in the moroccan stock market during the financial crisis. Empirical Economics, 52(4), 1481-1504. https://doi.org/10.1007/s0018.

Engle, R. (2002). Dynamic conditional correlation: A simple class of multivariate generalized autoregressive conditional heteroskedasticity models. Journal of Business \& Economic Statistics, 20(3), 339-350. https://doi.org/10.1198/073500102288618487

Gulzar, S., Mujtaba Kayani, G., Xiaofeng, H., Ayub, U., \& Rafique, A. (2019). Financial cointegration and spillover effect of global financial crisis: A study of emerging asian financial markets. Economic Research-Ekonomska Istra zivanja, 32(1), 187-218. https://doi.org/10.1080/1331677X.2018.1550001.

Johansen, S. (1991). Estimation and hypothesis testing of cointegration vectors in gaussian vector autoregressive models. Econometrica: Journal of the Econometric Society, 1551-1580. https://doi.org/10.2307/2938278

Kirkulak Uludag, B., \& Ezzat, H. (2017). Volatility spillover effect in mena stock markets: Evidence from pre-and postegyptian revolution. Journal of Yasar University, 12(45).

Kuttu, S. (2014). Return and volatility dynamics among four african equity markets: A multivariate var-egarch analysis. Global Finance Journal, 25(1), 56-69. https://doi.org/10.1016/j.gfj.2014.03.001

Li, Y., \& Giles, D. E. (2015). Modelling volatility spillover effects between developed stock markets and asian emerging stock markets. International Journal of Finance \& Economics, 20(2), 155-177. https://doi.org/10.1002/ijfe.1506.

Liebenberg, F. J. N. (2012). The volatility spillover effect of a dual-listed stock for international markets. PhD thesis, Citeseer.

Liew, V. K. S. (2004). Which lag length selection criteria should we employ? Economics bulletin, 3(33), 1-9.

Mensi, W., Beljid, M., Boubaker, A., \& Managi, S. (2013). Correlations and volatility spillovers across commodity and stock markets: Linking energies, food, and gold. Economic Modelling, 32, 15-22. https://doi.org/10.1016/j.econmod.2013.01.023

Phume, M. P., \& Bonga-Bonga, L. (2018). Return and volatility spillovers between south african and nigerian equity markets.

Shettima, M. A., Gambo, A. I., Abraham, O., Adamu, H. D., \& Gadanya, B. S. (2019). Return and volatility spillovers between ghanaian and nigerian equity markets. International Journal of Economics, Business and Management Research.

Tsay, R. S. (2010). Financial Time Series. Wiley Online Library. https://doi.org/10.1002/9780470644560

\section{Copyrights}

Copyright for this article is retained by the author(s), with first publication rights granted to the journal.

This is an open-access article distributed under the terms and conditions of the Creative Commons Attribution license (http://creativecommons.org/licenses/by/4.0/). 